\title{
Respiratory viruses associated with patients older than 50 years presenting with ILI in Senegal, 2009 to 2011
}

Ndongo Dia ${ }^{1}$, Vincent Richard ${ }^{2}$, Davy Kiori', El Hadj Abdoul Khadir Cisse', Fatoumata Diène Sarr ${ }^{2}$, Abdourahmane Faye ${ }^{1}$, Déborah G Goudiaby¹, Ousmane M Diop ${ }^{1}$ and Mbayame N Niang ${ }^{1 *}$

\begin{abstract}
Background: In Africa, especially in West Africa, studies about the prevalence and diversity of respiratory viruses (influenza and others) in elderly people are largely lacking. In studies done elsewhere, it is well established that older people, when compared with younger adults, are at greater risk of significant morbidity and mortality from complications arising from influenza. The main aim of this study was to determine the prevalence and the diversity of respiratory viruses associated with ILI cases in adults over 50 years old in Senegal.

Methods: The recruitment period of this study was from January 2009 to December 2011. 232 patients aged 50 years and above presenting ILI cases were enrolled. Nasal-pharyngeal and/or oral pharyngeal swabs were collected from patients. RNA was extracted from $200 \mu \mathrm{l}$ of each sample followed by a two-step real-time RT-PCR. The Anyplex ${ }^{\mathrm{TM}}$ II RV16 Detection kit was used for viral detection. The kit enabled the simultaneous detection of the presence of 16 respiratory viruses.

Results: 150 viruses were detected: influenza viruses (44.7\%) and rhinoviruses (26.7\%) were the most prevalent. We detected 13 human parainfluenza viruses (8.7\%), 7 human respiratory syncytial viruses (4.7\%), 6 coronaviruses (4\%), 5 human metapneumoviruses (3.3\%), 5 human adenoviruses (3.3\%) and 1 human bocavirus (0.7\%). 14 cases (6\%) of dual virus infections and one triple viral detection case were encountered. 56 (56.6\%) viruses detected were found in the 50-64 year old age group, $59(76.6 \% ; \mathrm{P}<0.001)$ from $65-74$ year old age group and $35(62.5 \%)$ were detected in the $\geq 75$ year old age group. The viral co-infections were more frequent in the 65-74 age group (9/15).

Conclusions: This pilot study demonstrates a variety of respiratory viruses in the elderly. It also highlights a high prevalence of these viruses in this age group. We speculate from these results that the impact of respiratory viruses other than influenza on the elderly has been considerably underestimated. A more exhaustive study seems necessary in order to provide a more complete picture of the burden of respiratory viruses on morbidity among adults over 50 years old in the sub-Saharan context.
\end{abstract}

Keywords: Influenza, Respiratory virus, Elderly, Prevalence, Diversity

\footnotetext{
* Correspondence: niang@pasteur.sn

'Unit of Medical Virology, Institut Pasteur de Dakar, Unité de Virologie Médicale, Dakar, BP; 220, Dakar, Senegal

Full list of author information is available at the end of the article
} 


\section{Background}

Viral aetiology, prevalence and diversity data in people with influenza like illness (ILI) and/or acute respiratory illness (ARI) in Africa, (especially in West Africa), are scarce and often limited to the influenza viruses' infection. Following the last influenza pandemic episode [1], few global and pediatric studies were conducted in some countries of the sub-region [2-4], and only a limited number of studies have described the etiology of ILI due to viruses including non-influenza respiratory virus [5-7]. However, no study has been conducted to describe the prevalence and the diversity of respiratory viruses (influenza and others) in West African elderly people. In studies done elsewhere, it is well established that older people, when compared with younger adults, are at greater risk of significant morbidity and mortality from complications arising from influenza $[8,9]$. For example in the United States alone, up to $40 \%$ of non-pneumonic lower respiratory illnesses in the elderly have been associated with respiratory viral infection [10], and an estimated 54,000 deaths annually have been attributed to the influenza and respiratory syncytial viruses (RSV) [11].

It should be highlighted that in Senegal the number of elderly people in consultation in healthcare centers for influenza like illness (ILI) is very low. Indeed, routine influenza monitoring in Senegal showed that samples from people above 50 years old represent only 3.7\% of the total, over a 16 year surveillance period [4]. Some practices such as auto-medication and the use of traditional medicine to treat ILI largely explain this situation with the socio-economic situation being another contributing factor.

Thus the main aim of this study was to determine the prevalence and the diversity of respiratory viruses associated with ILI cases in adults over 50 years old.

\section{Methods}

\section{Recruitment and samples}

The recruitment period of this prospective observational study was from January 2009 to December 2011 inclusive. All 232 patients aged 50 years and above presenting with ILI during this period were enrolled in the study. It should be noted that samples were collected in the context of flu monitoring. An influenza sentinel surveillance system for outpatients with ILI was established in 1996 in Senegal and became part of the WHO Global Influenza Surveillance and Response System (GISRS). It is coordinated locally by the National Influenza Center (NIC) at the Institut Pasteur de Dakar.

Trained medical personnel were asked to screen all outpatients who were attended at the sentinel sites for signs and symptoms of ILI. The symptoms of influenza are similar to those arising from other viral respiratory pathogens. The inclusion criteria, according to the CDC case definition, were sudden onset of fever $\left(\geq 38^{\circ} \mathrm{C}\right)$ with cough or sore throat fewer than 3 days in duration. Nasal-pharyngeal and/or oral-pharyngeal swabs were collected from each enrolled ILI case, placed in cryovials containing $3 \mathrm{ml}$ of viral transport medium (Universal Transport Medium, COPAN Diagnostics Inc., Murrieta, CA, USA) and stored at $4^{\circ} \mathrm{C}$ on site. If nasal-pharyngeal and oral-pharyngeal swab specimens were collected from the same patient, both swabs were placed in the same cryovial. Upon arrival at the laboratory the specimens were separated into 3 aliquots for analyses. The first aliquot was used for molecular analysis for the detection of influenza viruses (real-time reverse transcription polymerase chain reaction or rRT-PCR detection), the second was used for influenza virus isolation, and the third was stored at $-80^{\circ} \mathrm{C}$ for further analysis. The latter was used in the present study.

For each patient who met the case definition criteria, a form collecting demographic and clinical data was completed.The questions included information on date of enrollment and symptom onset, sex, age, clinical symptoms, previous treatments, vaccination status for influenza, and whether or not the patient was hospitalized.

\section{RNA extraction from clinical samples}

Ribonucleic acid (RNA) extraction was performed from $200 \mu \mathrm{l}$ of each sample using the QIAamp Viral RNA kit (QIAGEN, Valencia, CA, USA) according to the manufacturer's instructions. Each RNA sample was eluted with $100 \mu \mathrm{l}$ nuclease-free water before RNA quantification with a Nanodrop apparatus (NanoDrop Lite, Thermo Scientific).

\section{Detection of respiratory viruses}

A two-step real-time RT-PCR was performed using the CFX96 Real-Time PCR Detection System (Bio-Rad).

\section{CDNA synthesis step}

The RevertAid First Strand cDNA Synthesis Kit (Thermo Scientific) was used. First 1 ng of RNA was mixed with $1 \mu \mathrm{l}$ of random hexamer primer and nuclease free water for a final volume of $10 \mu \mathrm{l}$. It was then incubated at $65^{\circ} \mathrm{C}$ for 5 minutes and immediately put on ice in order to remove the secondary structures in GC-rich RNA.

For the cDNA synthesis step, $4 \mu \mathrm{l}$ of $5 \mathrm{X}$ reaction buffer, $1 \mu \mathrm{l}$ of RNase inhibitor $(20 \mathrm{u} / \mu \mathrm{l}), 2 \mu \mathrm{l}$ of dNTP Mix $(10 \mathrm{mM})$ and $1 \mu \mathrm{l}$ of RevertAid M-MuLV Reverse Transcriptase $(200 \mathrm{u} / \mu \mathrm{l})$ were added and incubated for 5 minutes at $25^{\circ} \mathrm{C}$ followed by 60 minutes at $42^{\circ} \mathrm{C}$ and $70^{\circ} \mathrm{C}$ for 5 minutes. The cDNA product could be used directly for the next step (PCR amplification) or stored at $-80^{\circ} \mathrm{C}$ until use. 


\section{PCR detection}

For viral detection, the Anyplex ${ }^{\mathrm{Tm}}$ II RV16 Detection kit (Seegene) was used. The Kit enabled simultaneous detection of influenza A virus, influenza B virus, human respiratory syncytial virus $\mathrm{A}$, human respiratory syncytial virus $B$, human adenovirus, human metapneumovirus, human coronavirus 229E, human coronavirus NL63, human coronavirus OC43, human parainfluenza virus $-1,-2,-3,-4$, human rhinovirus $\mathrm{A} / \mathrm{B} / \mathrm{C}$, human enterovirus and human bocavirus.

Reactions are duplicated in two panels (A and B) for detection of the 16 viruses. The total reaction volume was $20 \mu \mathrm{l}$ for each sample (for each panel), containing $4 \mu \mathrm{l}$ 5X RV16 A (or 5X RV16 B), $4 \mu \mathrm{l}$ of 8-MOP solution, $4 \mu \mathrm{l}$ of $5 \mathrm{X}$ Anyplex PCR Master Mix (mix well by inverting 5 times) and $8 \mu$ lof cDNA product. PCR was assessed after $95^{\circ} \mathrm{C}$ for 15 minutes for transcriptase reverse enzyme inactivation, 50 cycles of $95^{\circ} \mathrm{C}$ for 30 seconds, $60^{\circ} \mathrm{C}$ for 60 seconds and $72^{\circ} \mathrm{C}$ for 30 seconds. 1 additional cycle of $55^{\circ} \mathrm{C}$ for 30 seconds was added for completion. The fluorescence is detected with a melting curve step, $55^{\circ} \mathrm{C}-85^{\circ} \mathrm{C}$ (5 seconds $/ 0.5^{\circ} \mathrm{C}$ ).

\section{Statistical analysis}

Fisher's exact test was used to verify whether the associated proportions were statistically supported and a p-value $<0.05$ was considered statistically significant. We used the 50-64 year' old group as the reference. The R.15.1 tool was used to perform the analyses.

\section{Ethical considerations}

The Senegalese National Ethical Committee of the Ministry of Health approved the surveillance protocol as less than minimal risk research, and written consent forms were not required. Throughout the study, the database was shared with the Epidemiology Department at the Senegalese Ministry of Health and Prevention for appropriate public health action.

\section{Results}

\section{Demographic and clinical information}

A total of 232 patients above 50 years old were enrolled into the study, 129 (55.8\%) were women and 102 (44.2\%) were men (Table 1). Patients' ages ranged from 51 to 97 years, with a mean age of 66 years. Ninety-nine (42.7\%) enrolled patients were between 51 and 64 years old, 77 (33.2\%) between 65 and 74 years old and 56 (24.1\%) were 75 years old or older.

Fever was the most reported clinical symptom, in 213 $(92.2 \% ; 213 / 232)$ of the enrolled patients, followed by cough (80.2\%; 186/232), rhinitis (75.9\%; 176/232), myalgia (53.9\%; 125/232) and pharyngitis (44\%; 102/232).
Table 1 Demographical, viral detection and clinical data

\begin{tabular}{|c|c|c|c|c|}
\hline \multicolumn{5}{|c|}{ Age groups } \\
\hline $\begin{array}{l}\text { Demographical } \\
\text { data }\end{array}$ & $\begin{array}{l}50-64 \text { y } \\
(\mathrm{n}=99)\end{array}$ & $\begin{array}{l}65-74 y \\
(n=77)\end{array}$ & $\begin{array}{c}\geq 75 \\
(n=56)\end{array}$ & $\begin{array}{l}\text { Total } \\
\text { n (232) }\end{array}$ \\
\hline Mean age & $56 y$ & $70 y$ & $81 \mathrm{y}$ & $66 y$ \\
\hline \multicolumn{5}{|l|}{ Gender } \\
\hline \multicolumn{5}{|l|}{ no. (\%) } \\
\hline Female & $55(55.5 \%)$ & 41 (53.9\%) & $33(58.9 \%)$ & $129(55.8 \%)$ \\
\hline Male & $44(44.5 \%)$ & $35(46.1 \%)$ & $23(41.1 \%)$ & $102(44.2 \%)$ \\
\hline $\begin{array}{l}\text { Viral detection } \\
\text { rates }\end{array}$ & 56 (56.6\%) & 59 (76.6\%) & 35 (62.5\%) & $150(64.6 \%)$ \\
\hline \multicolumn{5}{|l|}{ Clinical data } \\
\hline \multicolumn{5}{|l|}{ no. (\%) } \\
\hline Fever & 89 (89.9\%) & 71 (93.4\%) & 49 (87.5\%) & 209 (90.5\%) \\
\hline Cough & 70 (70.7\%) & 68 (89.4\%) & $48(85.7 \%)$ & $186(80.5 \%)$ \\
\hline Rhinitis & 68 (68.7\%) & 67 (88.2\%) & $41(73.2 \%)$ & $176(76.2 \%)$ \\
\hline Myalgia & 35 (35.3\%) & $59(77.6 \%)$ & $32(57.0 \%)$ & $126(54.5 \%)$ \\
\hline Pharyngitis & $26(26.3 \%)$ & 48 (63.2\%) & $28(50.0 \%)$ & $102(44.2 \%)$ \\
\hline Sore throat & $41(41.4 \%)$ & $32(42.1 \%)$ & $23(41.1 \%)$ & $96(41.4 \%)$ \\
\hline Laryngitis & $02(2.0 \%)$ & $20(26.3 \%)$ & $13(23.2 \%)$ & 35 (15.1\%) \\
\hline Headache & $13(13.1 \%)$ & $08(10.5 \%)$ & 04 (7.1\%) & $25(10.8 \%)$ \\
\hline Dyspnea & 02 (2.0\%) & 05 (6.6\%) & $04(7.1 \%)$ & 11 (4.8\%) \\
\hline
\end{tabular}

\section{Viral detection}

In all, 132 (56.9\%) out of the 232 patients were found to be infected with at least one of the viruses of interest. A total of 150 (64.6\% of patients) viruses were detected. Of these viruses, Influenza viruses $(44.7 \% ; 67 / 150)$ and rhinoviruses $(26.7 \%$; 40/150) were the most prevalent viruses detected (Table 2). We detected 13 human parainfluenza viruses (3 PIV1, 4 PIV3, 6 PIV4) (8.7\%), 7 human respiratory syncytial viruses (6 RSV A and 1 RSV B) $(4.7 \%), 6$ coronaviruses (4 coronaviruses NL63, one coronaviruses 229E and one coronavirus OC43) (4\%), 5 human metapneumoviruses (3.3\%), 5 human adenoviruses (3.3\%) and one human bocavirus $(0.7 \%)$.

A total of 14 cases (6\%) of dual virus infections and one triple viral detection case were encountered. Influenza viruses (13 cases) and rhinoviruses (8 cases) were the most common type of virus found in samples with coinfections.

Regarding the number of viruses detected per age group, 56 (56.6\%; 56/99) were from the 50-64 age group, 59 (76.6\%; 59/77; $\mathrm{P}<0.001)$ from the $65-74$ year old age group and $35(62.5 \%$; $35 / 56)$ were detected in the older than 75 year old age group (Table 2). The viral coinfections are more frequent in the 65-74 year old age group (9/15) followed by the $\geq 75$ years group (4/15).

Taking into account the clinical symptoms and viral detection, cough, rhinitis, pharyngitis or headache were in similar proportion in viral positive and non-positive patients: cough was observed in $79.4 \%$ of positive 
Table 2 Viral etiology of influenza-like illness cases in adults aged above 50 years in Senegal during 2009-2011

\begin{tabular}{ccccc}
\hline & \multicolumn{4}{c}{ Age groups } \\
\cline { 2 - 5 } Viral detection & $\begin{array}{c}\mathbf{5 0 - 6 4} \mathbf{y} \\
\mathbf{( n = 9 9 )}\end{array}$ & $\begin{array}{c}\mathbf{6 5 - 7 4} \mathbf{y} \\
\mathbf{( n = 7 7 )}\end{array}$ & $\begin{array}{c}\mathbf{2 7 5} \\
\mathbf{( n = 5 6 )}\end{array}$ & $\begin{array}{c}\text { Total } \\
\mathbf{n}(\mathbf{2 3 2})\end{array}$ \\
\hline Virus detected/n (\%) & $\begin{array}{c}\mathbf{5 6} \\
\mathbf{( 5 6 . 6 \% )}\end{array}$ & $\begin{array}{c}\mathbf{5 9} \\
\mathbf{( 7 6 . 6 \% )}\end{array}$ & $\begin{array}{c}\mathbf{3 5} \\
\mathbf{6 2 2 . 5 \% )}\end{array}$ & $\begin{array}{c}\mathbf{1 5 0} \\
\mathbf{6 6 4 . 6 \% )}\end{array}$ \\
\hline Influenza A & $24(24.2 \%)$ & $20(26 \%)$ & $8(14.3 \%)$ & $52(22.4 \%)$ \\
\hline Influenza B & $4(4.0 \%)$ & $10(13 \%)$ & $1(1.8 \%)$ & $15(6.5 \%)$ \\
\hline RSV & $2(2.0 \%)$ & $3(3.9 \%)$ & $2(3.6 \%)$ & $7(3.0 \%)$ \\
\hline Rhinovirus & $12(12.1 \%)$ & $16(20.8 \%)$ & $12(21.4 \%)$ & $40(17.2 \%)$ \\
\hline Parainfluenza & $3(3.0 \%)$ & $5(6.5 \%)$ & $5(8.9 \%)$ & $13(5.6 \%)$ \\
\hline Coronavirus & $6(6.0 \%)$ & $0(0.0 \%)$ & $0(0.0 \%)$ & $6(2.3 \%)$ \\
\hline HMPV & $3(3.0 \%)$ & $1(1.3 \%)$ & $1(1.8 \%)$ & $5(2.2 \%)$ \\
\hline Enterovirus & $2(2.0 \%)$ & $3(3.9 \%)$ & $1(1.8 \%)$ & $6(2.3 \%)$ \\
\hline Adenovirus & $0(0.0 \%)$ & $0(0.0 \%)$ & $5(8.9 \%)$ & $5(2.2 \%)$ \\
\hline Bocavirus & $0(0.0 \%)$ & $1(1.3 \%)$ & $0(0.0 \%)$ & $1(0.4 \%)$ \\
\hline Codetections & $2(2.0 \%)$ & $9(11.7 \%)$ & $4(7.1 \%)$ & $15(6.5 \%)$ \\
\hline
\end{tabular}

patients and $77 \%$ in the negative patients group $(\mathrm{P}=0.17)$, rhinitis $79.4 \%$ and $67 \%(\mathrm{P}=0.04)$, pharyngitis in $45.8 \%$ and $42 \%(\mathrm{P}=0.74)$ respectively. In contrast myalgia symptoms are significantly higher among viral-positive patients: $76.3 \%$ versus $25 \%(\mathrm{P}<0.001)$.

The pattern of the virus detection throughout the study period is showed in the Figure 1. Influenza viruses (A and B) were mostly detected from July to August (between weeks 28 and 43), which corresponds to the rainy season in Senegal. A minor detection peak is also registered at the beginning of the year. Rhinoviruses and parainfluenza viruses showed homogeneous detection levels throughout the study period. Grouped, the remaining viruses seemed to have a similar temporal pattern to that of influenza viruses. The gap observed between weeks 18 and 22 correspond with a lack of samples from patients from our targeted age group.

\section{Discussion}

The present study is the first description of the etiology of respiratory viruses associated with patients with ILI in a cohort of elderly people in the West African context. The results obtained showed that 132 samples of the study population out of 232 contained at least one of the targeted respiratory viruses.

The frequency of virus detection (56.9\%) among the elderly with ILI in our study is consistent with that of several studies already conducted. Huo et al. (2012) [12], in a similar study in China detected at least one respiratory virus in $53 \%$ of patients 60 years old or older, and Munoz et al. (2000) [13] 49\% in elders in a long term care facilities in Ontario during the 1998-1999 period. Hasman et al. (2009) [14] detected at least one respiratory virus in $68 \%$ patients in a study conducted in USA, without any precision about the ages of the 154 adults. In others studies frequencies are lower. For example Nicholson et al. (1997) [15] 43\% (211/497) of viral detection among the elderly between 60 and 90 years of old, 36\% (185/512) detected in the elderly over 65 years old in a study in China [16] and 22.2\% in a recent study in Japan [17]. It is important to note that the technical approach used explains some discrepancies in rates of detection: primarily in their sensitivity and secondly in the number of targeted viruses. Alternatively differences in rates of detection could be due to true geographical differences in overall burden, differences in study populations (outpatients or hospitalized patients) and to the studies sample collection periods. Overall, the viral detection rate in the present study is very high as elderly people are often protected by pre-existing antibodies from previous illnesses, maybe illnesses suffered even decades back [18-20]. Indeed, because of pre-existing systemic and mucosal antibodies, elderly adults have been observed to have lower amounts of respiratory secretions and lower viral loads compared to children [10]. Consistent

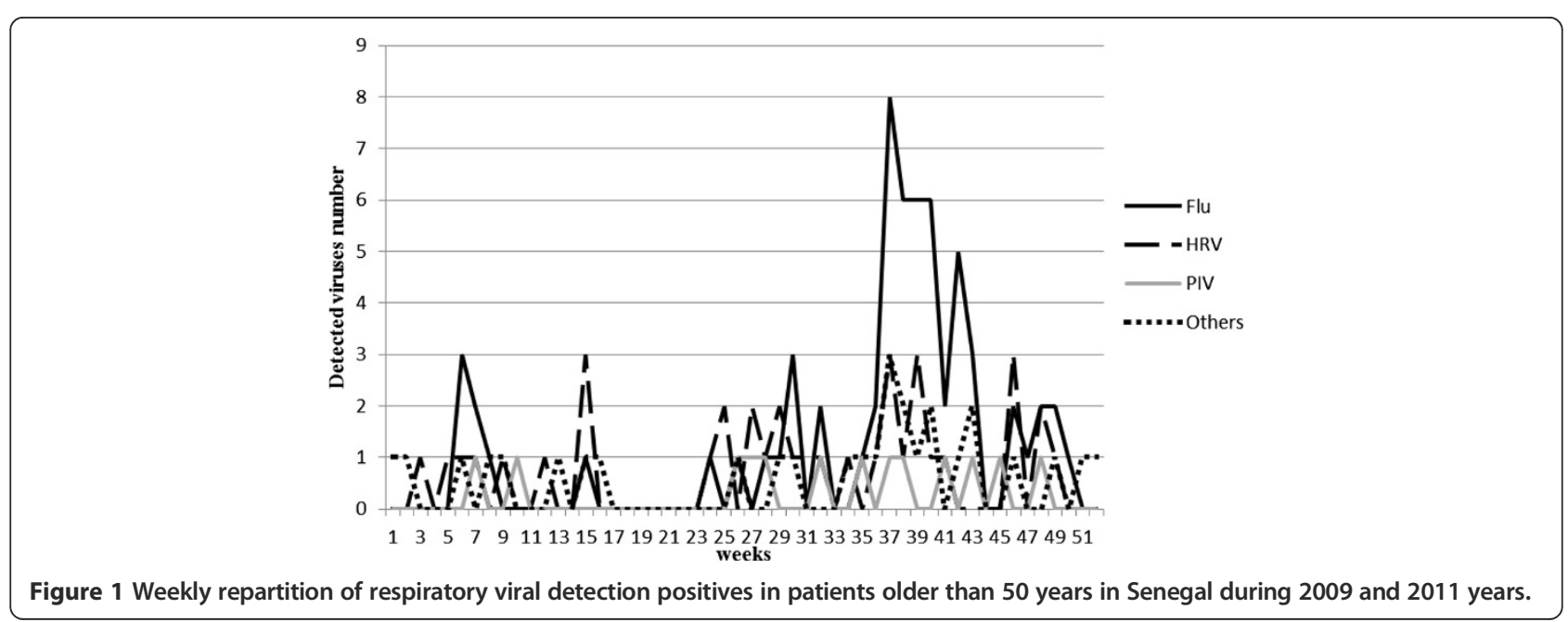


with this hypothesis, Falchi et al. (2011) [21] noted that the age distribution differed significantly between positive and negative patients, with positive patients being younger than negative patients $(\mathrm{OR}=0.98$, IC 0.95- 0.99; $\mathrm{P}=0.0226)$.

Of the 150 viruses detected in the elderly, influenza A virus was the most common viral pathogen. Combined with influenza B viruses, influenza viruses represented $45 \%(67 / 150)$ of viruses detected. This influenza detection rate was expected as the enrollment of patients was directed towards patients with ILI. These results are in agreement with previous findings in the elderly $[14,17,22]$. Our study revealed a high detection rate of rhinoviruses (40/150; 26.7\%). Rhinovirus is the most common respiratory pathogen in all age groups [23]. In a previous study, Nicholson et al. (1997) [15] showed that rhinoviruses were responsible for a greater disease burden (activities restriction, duration of illness) than that of influenza in elderly subjects representing $52 \%$ of detected viruses. In another study published by Greenberg (2002) [24], rhinovirus was the most prevalent pathogen (121 isolates; $53 \%$ ) of the 231 identified in upper respiratory episodes. These findings are in concordance with the high rhinovirus detection rate in the present study.

With lower prevalence, PIV, RSV, HCoV, HMPV, enteroviruses, adenoviruses and bocaviruses were identified from elderly patient' specimens and contributed collectively to $28.7 \%$ of all ILI cases in our study. These results show the high diversity of respiratory viruses circulating in the elderly population. This viral diversity supports previous results $[10,12,24]$ and often in similar distributions with those of the present study.

Co-infections were relatively common in this study especially in the 65-74 years old age group (11.7\%; 9/77). The rate found in this age group was in line with the findings of Hasman et al. (2009) [14] (11\%) and Huo et al. (2012) [12], 11.7\%. Huo and colleagues, in agreement with our results noted that co-infections were found most commonly in adults older than 60 years of age.

Focusing on clinical symptoms, with the exception of myalgia, our study showed no significant differences between viral-positive and viral- negative patients with ILI.

Viral circulation observed during the study period showed different patterns depending on the viral types. If we consider influenza viruses, we observed a circulation peak during the period starting in week 35 and ending in week 44. This period corresponds to the middle of the rainy season in Senegal. This result is further supported by a recent study conducted by Mbayame and colleagues [4]. These authors established clearly the seasonality of influenza viruses in Senegal after many years of surveillance with a regular circulation during the year and a peak in the middle of the rainy season (July-August-September). The slight peak of influenza observed at the beginning of the year (February) is the result of the shift caused by the recent pandemic episode. The pandemic occurred in early 2010 in Senegal with a peak in February [25]. Rhinoviruses showed a regular yearly circulation with peaks along the year corresponding to any rain season influence. The remaining respiratory viruses (PIV, RSV, $\mathrm{HCoV}, \mathrm{HMPV}$, enterovirus, adenovirus and bocavirus) were more likely associated with ILI peak during the rainy season. This co-circulation with influenza viruses was also seen in a previous pediatric study in Senegal [6]. Further studies (multiple year surveillance) are needed in order to properly define the temporal patterns of non-influenza virus circulation in Senegal.

Our study did have several limitations. The first weakness is the small number of samples treated in this study. A more exhaustive sampling would give a better representation of the different targeted viruses in the ILI cases among the elderly population in Senegal. Unfortunately after 16 years of influenza sentinel monitoring we noted that the number of elderly presenting at healthcare centers for ILI consultation is rather low compared to other age groups (children and young adults). The absence of nursing home services as in industrial countries, the use of traditional medicine (especially among the elderly) and economic constraints do not facilitate such studies in the West African context.

It is worth noting that this was a retrospective study, the database contained limited information on disease outcome and atypical clinical symptoms in ILI patients which were not reported. Thus the association between viral infections (or co-infections) and severe signs could not be established. As in previous studies it appears that co-infections were associated with more severe signs than mono-infections $[26,27]$. Without such data we could not measure the burden of targeted respiratory viruses in older patients with ILI. Another limitation is that our study is only focused on outpatient' cases; it would be interesting to investigate hospitalized patient cases (severe cases). A final limitation was that the study included mainly one geographic location, Dakar, the capital city of Senegal.

\section{Conclusion}

Despite the small number of samples included, the present pilot study demonstrates a variety of respiratory viruses in the elderly. It also highlights a high prevalence of these viruses in this cohort. From these results, it appears that the impact of respiratory viruses other than influenza was considerably underestimated. A more exhaustive study (increasing the number of elderly patients, with a better clinical picture and better documentation including disease outcomes, illness duration, hospitalizations etc.), relying on the new sentinel surveillance system (extension of sentinel sites in others geographical areas), seems necessary in order to provide a more complete picture of the burden of respiratory viruses on morbidity among adults over 50 years old in the sub-Saharan context. 


\section{Abbreviations}

ILI: Influenza-like illness; rRT-PCR: Real-time reverse transcription polymerase chain reaction; WHO: World Health Organization; cDNA: Complementary deoxyribonucleic acid; RNA: Ribonuleic acid; GISN: Global Influenza Surveillance Network; NIC: National Influenza Center; PIV: Parainfluenza virus; RSV: Respiratory syncytial virus; HCoV: Human coronavirus; HMPV: Human metapneumovirus

\section{Competing interests}

The authors declare that they have no competing interests.

\section{Authors' contributions}

The work presented here was carried out in collaboration between all authors. MNN and OMD, defined the research and revised the manuscript; ND performed and coordinated technical work, wrote the draft and revisions of the paper; DK performed the main technical part of this work; EAKC and AF participated in the technical work; $D G$ and EAKC participated in data management and analysis; VR revised the manuscript and participated in the monitoring of the surveillance sites; FDS participated in the monitoring of the surveillance sites. All authors have contributed to, seen and approved the manuscript.

\section{Acknowledgements}

The authors thank Dr Abdou Salam Gueye, Associate Director for science at the US Centers for Disease Control (CDC) in Ivory Coast, for his great help in the revisions of this paper, especially for the English language. Many thanks to Oumy Niass (PhD student, Immunology Unit, IPD) for her help in the statistical analyses.

This work was funded by Institut Pasteur de Dakar, Senegal.

\section{Author details}

${ }^{1}$ Unit of Medical Virology, Institut Pasteur de Dakar, Unité de Virologie Médicale, Dakar, BP; 220, Dakar, Senegal. ${ }^{2}$ Institut Pasteur de Dakar, Unité d’Epidémiologie des maladies infectieuses, Dakar, Sénégal.

Received: 4 November 2013 Accepted: 3 April 2014

Published: 8 April 2014

\section{References}

1. Dawood FS, Jain S, Finelli L, Shaw MW, Lindstrom S, Garten RJ, Gubareva LV, Xu X, Bridges CB, Uyeki TM: Emergence of a novel swine-origin influenza A (H1N1) virus in humans. N Engl J Med 2009, 360:2605-2615.

2. Bonney JH, Kronmann KC, Lindan CP, Asante IA, Parbie P, Aboagye J, Amankwah J, Odoom JK, Adjabeng M, Nzussouo NT, Ahadzie L, Barthel RV, Cornelius C, Amofah G, Oyofo B, Ampofo WK: Virological surveillance of influenza-like illness among children in Ghana, 2008-2010. J Infect Dis 2012, 206(Suppl 1):S108-S113.

3. Dalhatu IT, Medina-Marino A, Olsen SJ, Hwang I, Gubio AB, Ekanem EE, Coker EB, Akpan H, Adedeji AA: Influenza viruses in Nigeria, 2009-2010: results from the first 17 months of a national influenza sentinel surveillance system. J Infect Dis 2012, 206(Suppl 1):S121-S128.

4. Niang MN, Dosseh A, Ndiaye K, Sagna M, Gregory V, Goudiaby D, Hay A, Diop OM: Sentinel surveillance for influenza in Senegal, 1996-2009. $J$ Infect Dis 2012, 206(Suppl 1):S129-S135.

5. Razanajatovo NH, Richard V, Hoffmann J, Reynes JM, Razafitrimo GM Randremanana RV, Heraud JM: Viral etiology of influenza-like illnesses in Antananarivo, Madagascar, July 2008 to June 2009. PLoS One 2011, 6(3):e17579. Doi: 10.1371/journal.pone.0017579.

6. Niang MN, Diop OM, Sarr FD, Goudiaby D, Malou-Sompy H, Ndiaye K, Vabret A, Baril L: Viral etiology of respiratory infections in children under 5 years old living in tropical rural areas of Senegal: the EVIRA project. J Med Virol 2010, 82(5):866-872.

7. Njouom R, Yekwa EL, Cappy P, Vabret A, Boisier P, Rousset D: Viral etiology of influenza-like illnesses in Cameroon, January-December 2009. J Infect Dis 2012, 206(Suppl 1):S29-S35.

8. Fleming DM, Elliot AJ: The impact of influenza on the health and health care utilisation of elderly people. Vaccine 2005, 23(Suppl1):S1-S9.

9. Newall AT, Wood JG, Macintyre CR: Influenza-related hospitalisation and death in Australians aged 50 years and older. Vaccine 2008, 26(17):2135-2141.

10. Jartti $L$, Langen $H$, Söderlund-Venermo M, Vuorinen $T$, Ruuskanen $O$, Jartti T: New respiratory viruses and the elderly. Open Respir Med J 2011, 5:61-69.
11. Thompson WW, Shay DK, Weintraub E, Brammer L, Cox N, Anderson LJ, Fukuda K: Mortality associated with influenza and respiratory syncytial virus in the United States. JAMA 2003, 289:179-186.

12. Huo X, Qin Y, Qi X, Zu R, Tang F, Li L, Hu Z, Zhu F: Surveillance of 16 respiratory viruses in patients with influenza-like illness in Nanjing, China. J Med Virol 2012, 84(12):1980-1984.

13. Munoz FM, Galasso GJ, Gwaltney JM Jr, Hayden FG, Murphy B, Webster R, Wright $P$, Couch RB: Current research on influenza and other respiratory viruses: II international symposium. Antiviral Res 2000, 46(2):91-124.

14. Hasman H, Pachucki CT, Unal A, Nguyen D, Devlin T, Peeples ME, Kwilas SA Aetiology of influenza-like illness in adults includes parainfluenzavirus type 4. J Med Microbiol 2009, 58(Pt 4):408-413.

15. Nicholson KG, Kent J, Hammersley V, Cancio E: Acute viral infections of upper respiratory tract in elderly people living in the community: comparative, prospective, population based study of disease burden. BMJ 1997, 315(7115):1060-1064.

16. Yang $Y$, Wang Z, Ren L, Wang W, Vernet G, Paranhos-Baccalà G, Jin Q, Wang J: Influenza A/H1N1 2009 pandemic and respiratory virus infections, Beijing, 2009-2010. PLoS One 2012, 7(9):e45807. doi: 10.1371/journal.pone.0045807. Epub 2012 Sep 20

17. Ikematsu H, Takeuchi Y, Rosenlund M, Kawai N, Shimamura R, Hirata M, Iwaki N: The post-infection outcomes of influenza and acute respiratory infection in patients above 50 years of age in Japan: an observational study. Influenza Other Respi Viruses 2012, 6(3):211-217.

18. Subbarao K, Klimov A, Katz J, Regnery H, Lim W, Hall H, Perdue M, Swayne D, Bender C, Huang J, Hemphill M, Rowe T, Shaw M, Xu X, Fukuda K, Cox N: Characterization of an avian influenza $A(H 5 N 1)$ virus isolated from a child with a fatal respiratory illness. Science 1998, 279:393-396.

19. Fowlkes AL, Arguin P, Biggerstaff MS, Gindler J, Blau D, Jain S, Dhara R, McLaughlin J, Turnipseed E, Meyer JJ, Louie JK, Siniscalchi A, Hamilton JJ, Reeves A, Park SY, Richter D, Ritchey MD, Cocoros NM, Blythe D, Peters S, Lynfield R, Peterson L, Anderson J, Moore Z, Williams R, McHugh L, Cruz C, Waters CL, Page SL, McDonald CK, et al: Epidemiology of 2009 pandemic influenza a (H1N1) deaths in the United States, April-July 2009. Clin Infect Dis 2011, 52(Suppl 1):S60-S68.

20. Centers for Disease Control and Prevention (CDC): Outbreaks of 2009 pandemic influenza $A(\mathrm{H} 1 \mathrm{~N} 1)$ among long-term-care facility residents-three states, 2009. MMWR Morb Mortal Wkly Rep 2010, 59:74-77.

21. Falchi A, Turbelin C, Andreoletti L, Arena C, Blanchon T, Bonmarin I, Hanslik T, Leruez-Ville M, De Lamballerie X, Carrat F: Nationwide surveillance of 18 respiratory viruses in patients with influenza-like illnesses: a pilot feasibility study in the French Sentinel network. J Med Virol 2011, 83:1451-1457.

22. Widmer K, Zhu Y, Williams JV, Griffin MR, Edwards KM, Talbot HK: Rates of hospitalizations for respiratory syncytial virus, human metapneumovirus, and influenza virus in older adults. J Infect Dis 2012, 206(1):56-62.

23. Knipe DM, Howley PM: Fields Virology. 5th edition. Philadelphia, PA: Lippincott Williams \& Wilkins; 2007.

24. Greenberg SB: Viral respiratory infections in elderly patients and patients with chronic obstructive pulmonary disease. Am J Med 2002, 112(Suppl 6A):28S-32S. Review.

25. Dia N, Ndiaye MN, Monteiro Mde L, Koivogui L, Bara MO, Diop OM: A subregional analysis of epidemiologic and genetic characteristics of influenza A(H1N1)pdm09 in Africa: Senegal, Cape Verde, Mauritania, and Guinea, 2009-2010. Am J Trop Med Hyg 2013, 88(5):946-953.

26. Frobert E, Escuret V, Javouhey E, Casalegno JS, Bouscambert-Duchamp M, Moulinier C, Gillet Y, Lina B, Floret D, Morfin F: Respiratory viruses in children admitted to hospital intensive care units: evaluating the CLART1 Pneumovir DNA array. J Med Virol 2011, 83:150-155.

27. Wolf DG, Greenberg D, Kalkstein D, Shemer-Avni Y, Givon-Lavi N, Saleh N, Goldberg MD, Dagan R: Comparison of human metapneumovirus, respiratory syncytial virus and influenza A virus lower respiratory tract infections in hospitalized young children. Pediatr Infect Dis J 2006, 25:320-324.

\section{doi:10.1186/1471-2334-14-189}

Cite this article as: Dia et al:: Respiratory viruses associated with patients older than 50 years presenting with ILI in Senegal, 2009 to 2011. BMC Infectious Diseases 2014 14:189. 